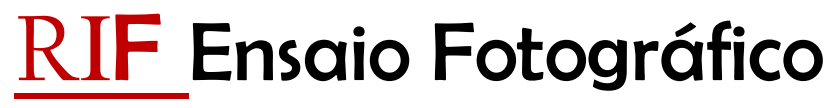

\author{
DOI - 10.5212/RIF.v.19.i42.0016
}

\section{Casas e descasos. Resistência e indiferenças}

Fotos e texto: Pedro Serico Vaz Filho ${ }^{1}$

O presente ensaio fotográfico traz como tema questões referentes às desigualdades urbanas, a partir de olhares sobre situações desrespeitosas à cidadania. Ao mesmo tempo acerca da resistência de quem não tem condições mínimas de sobrevivência, como a ausência de um teto, alimentação diária, viabilidade para higiene e saúde. Incluindo a falta de educação aos ambientes comuns, como nos transportes públicos, onde apelos educativos soam de autofalantes e são totalmente ignorados por quem joga lixo no chão, coloca pés em acentos, comete atos de assédios etc. Seria este um outro formato de pobreza, não exatamente de emprego e moradia, mas de consciência: “(...) a pobreza não é apenas uma categoria econômica, mas também uma categoria política acima de tudo. Estamos lidando com um problema social (SANTOS, 1978, p.10). A abordagem do geógrafo Milton Santos é sempre atual. Por referências como esta, de cidadania e educação, este ensaio fotográfico vem pela perspectiva de registros com câmera de aparelho celular. Dessa forma, para caracterizar originalidade ao fato destes instrumentos manuais de comunicação estarem presentes, e praticamente inseparáveis da população. Esta que tem a possibilidade de usar o mencionado instrumento móvel para realizar todos os tipos de registros em fotos, textos, áudios e vídeos.

\footnotetext{
Os celulares atuais são verdadeiros minicomputadores e, nesse contexto, os usuários estão pulando rapidamente dos serviços de voz para os de dados. Como resultado deste cenário e do aumento constante do consumo de telefone celular, há no mundo, atualmente, mais de sete bilhões de celulares em uso, quase se equiparando ao número de habitantes do planeta, segundo pesquisa da União Internacional de Telecomunicações (UIT) (JÚNIOR, 2015). Outro dado relevante é o papel que países emergentes como o Brasil desempenham neste cenário, pois ainda segundo a UIT, nestes estão a maioria dos celulares em uso em todo o planeta (SOARES e CÂMARA, 2017, p. 4).
}

\footnotetext{
1 Pós-doutor pela Escola de Comunicações e Artes da Universidade de São Paulo, CJE-ECA/USP; Doutor em Comunicação Social pela Universidade Metodista de São Paulo; Mestre em Comunicação pela Faculdade Cásper Líbero; Pós-graduado em Teoria e Técnicas da Comunicação pela Faculdade Cásper Líbero; Bacharel em Comunicação Social - habilitação em Jornalismo, pela FIAM. Correio eletrônico: pedrovaz@uol.br e professorpedrosericovazfilho@gmail.com
} 


\section{RIF, Ponta Grossa/PR Volume 19, Número 42, p.312-320, Janeiro/Junho 2021}

Os dados apresentados pelos estudos de Soares e Câmara provocam reflexões sobre o uso e volume de câmeras em celulares. Assim também pelas informações que por elas são recebidas, compartilhadas e comentadas, através de tais aparelhos, sobre situações diversas. Entre elas, cenas do cotidiano que podem causar admiração, seja pelo aspecto de indignação ou de apreciação de figuras, pessoas, espaços etc.

Em muitos casos notamos que imagens produzidas e enviadas via telefonia móvel, para meios de comunicação, passam a ter utilização e comentários que geram significativas audiências e acessos. Dependendo dos apelos temáticos são exibidas à exaustão em pautas como: o aumento de moradores de ruas, em espaços tidos como nobres. A exemplo da avenida Paulista, em São Paulo; áreas de preservação ambiental, ocupadas por construções irregulares, em terrenos com riscos de desabamentos e desmoronamentos. Entre assédios morais e sexuais e desrespeito à acessibilidade e às necessidades especiais. A contradição, no entanto, se fortalece, pois mesmo com tantos registros, campanhas, denúncias, publicações em mídias e legislações de defesa da cidadania e direitos humanos, os problemas sociais são crescentes, como é o aumento das aquisições de aparelhos celulares.

No presente trabalho, com imagens sobre situações sociais do cotidiano, as quais nos habituamos a ver e conviver, algumas fotos foram editadas para a preservação das pessoas envolvidas nos contextos.

\section{Foto 01: "Indiferença na Paulista"}

(Avenida Paulista, 807, em frente Edifício Sir Winston Churchill - outubro/2021)

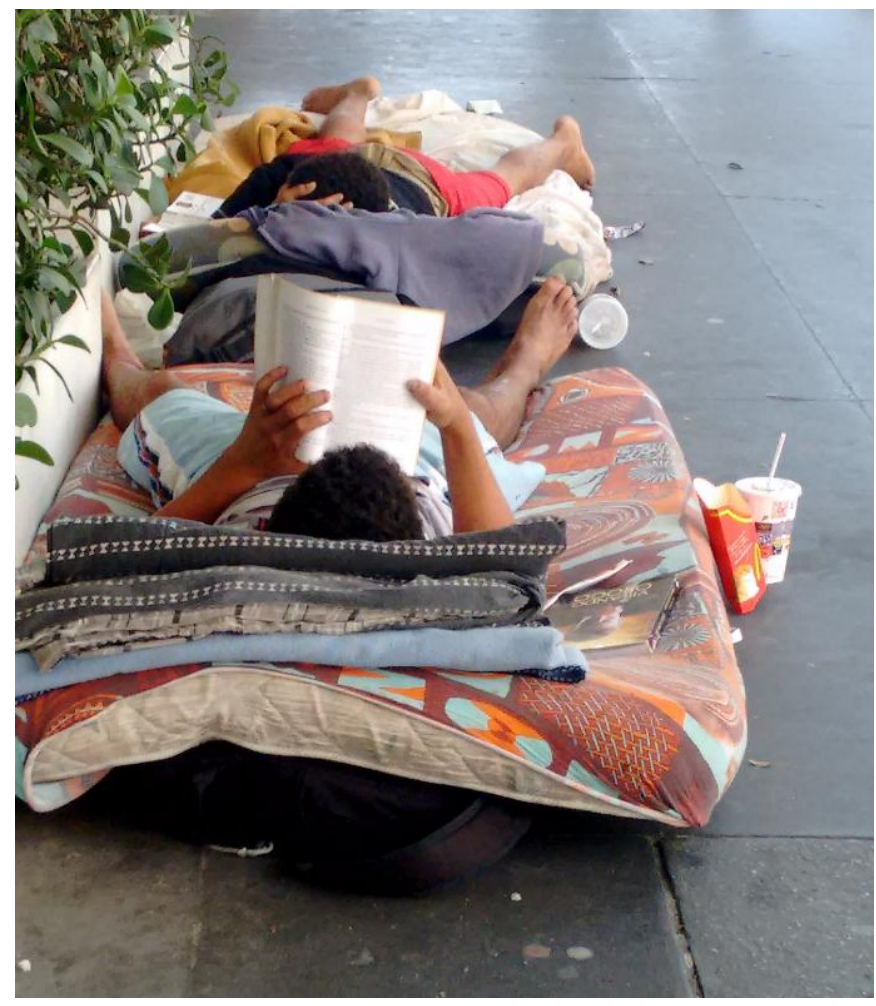


RIF, Ponta Grossa/PR Volume 19, Número 42, p.312-320, Janeiro/Junho 2021

Foto 02: "Porta de entrada"

(Morro do Zaíra, cidade de Mauá, São Paulo - fevereiro/2016)

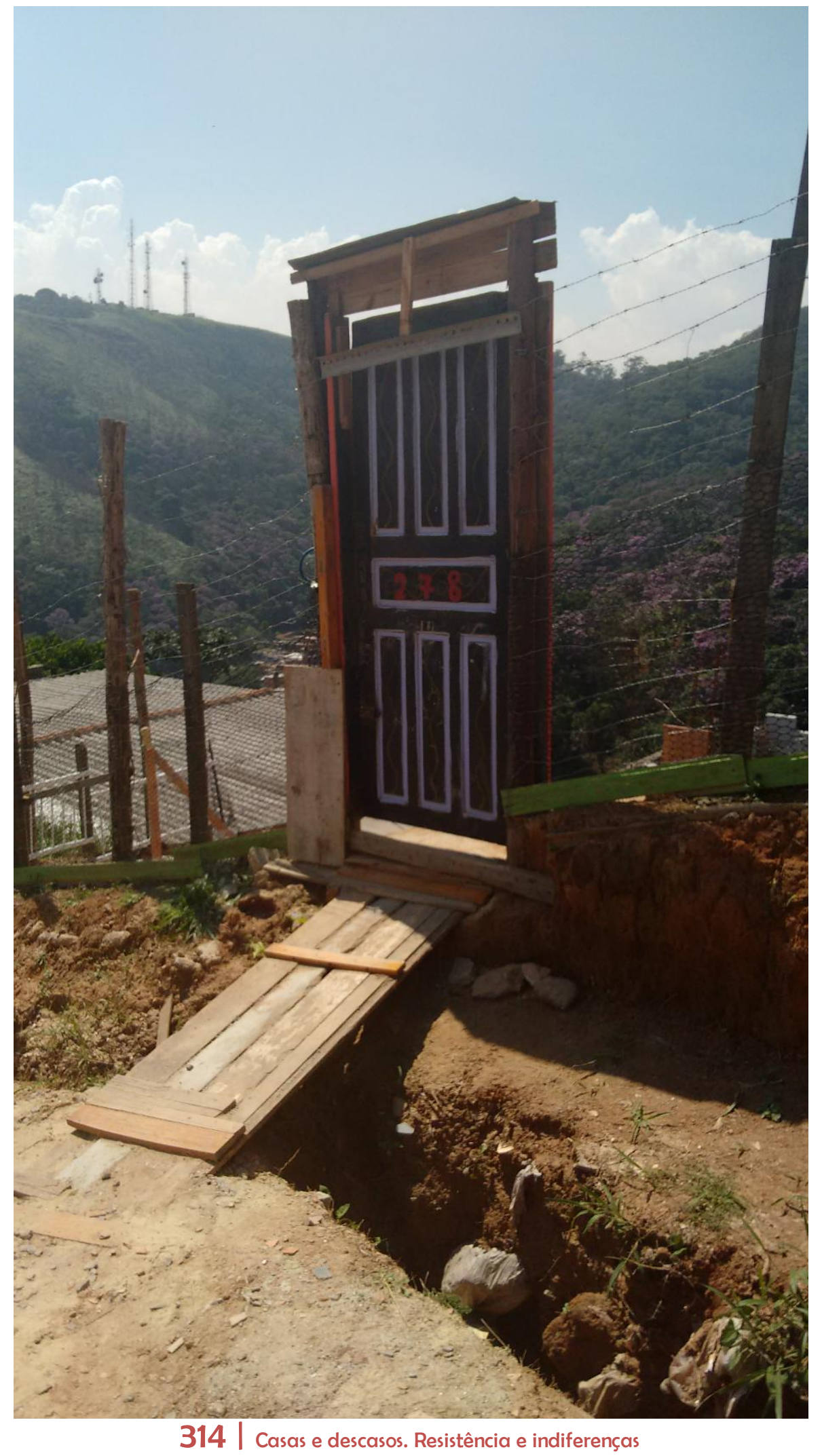


RIF, Ponta Grossa/PR Volume 19, Número 42, p.312-320, Janeiro/Junho 2021

Foto 03: "Convivência verde"

(Morro do Zaíra, cidade de Mauá, São Paulo - fevereiro/2016)

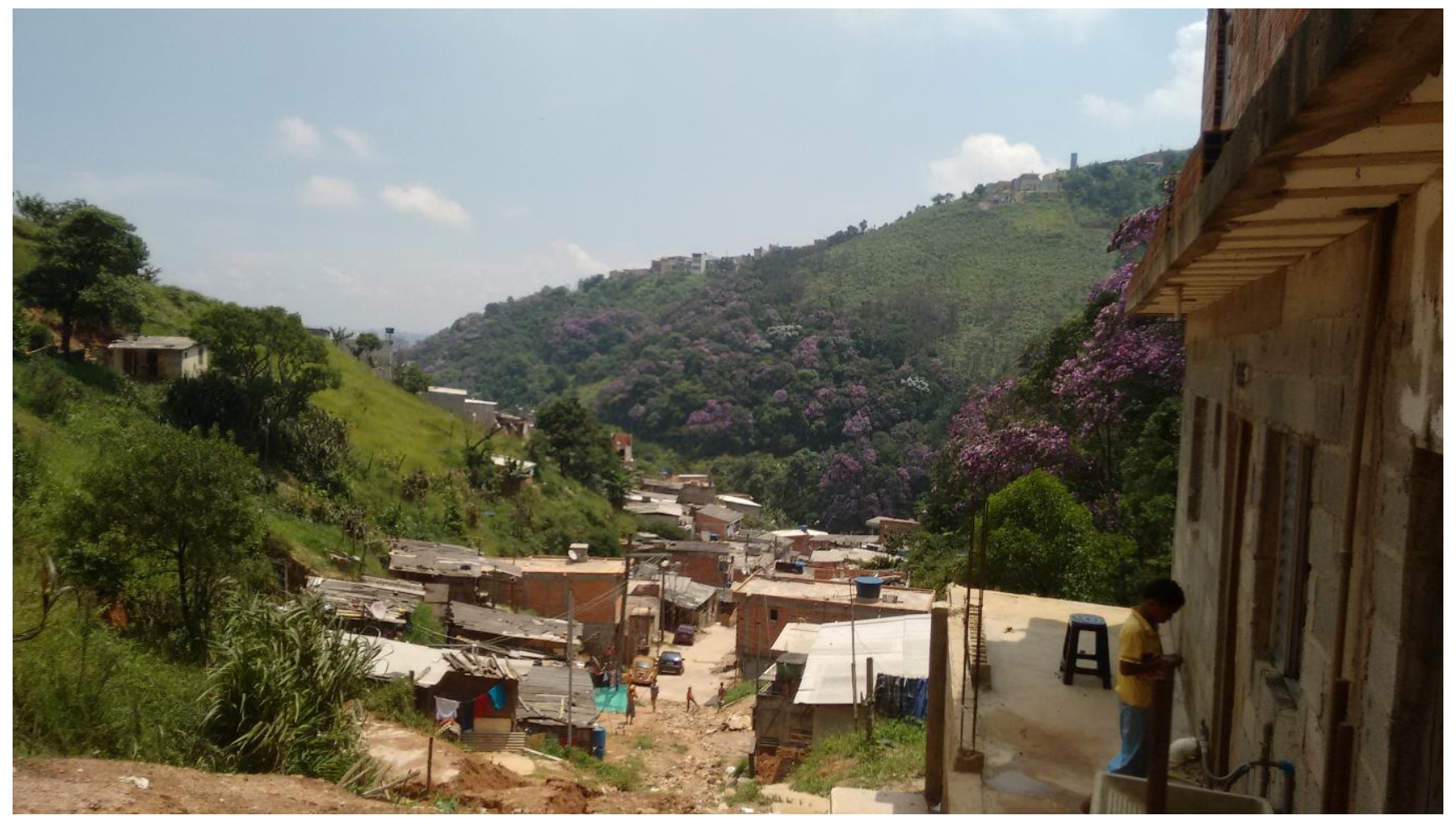

Foto 04: "Convivência humana"

(Morro do Zaíra, cidade de Mauá, São Paulo - fevereiro/2016)

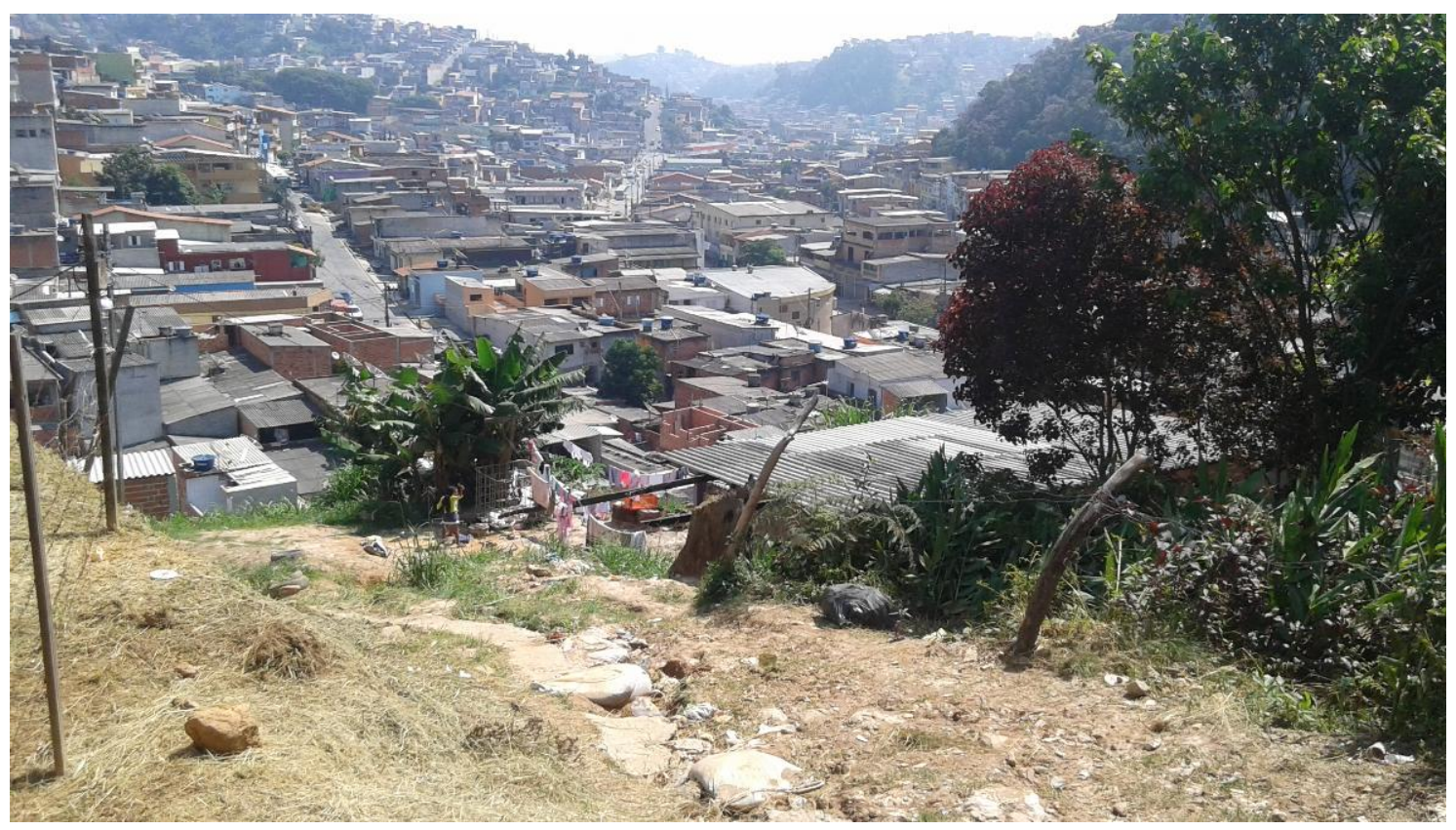

315 | Casas e descasos. Resistência e indiferenças 
RIF, Ponta Grossa/PR Volume 19, Número 42, p.312-320, Janeiro/Junho 2021

Foto 05: "Resistência na vertical”

(Rua do Paraíso, São Paulo - Alto do Edifício Dona Milene - dezembro/2020)

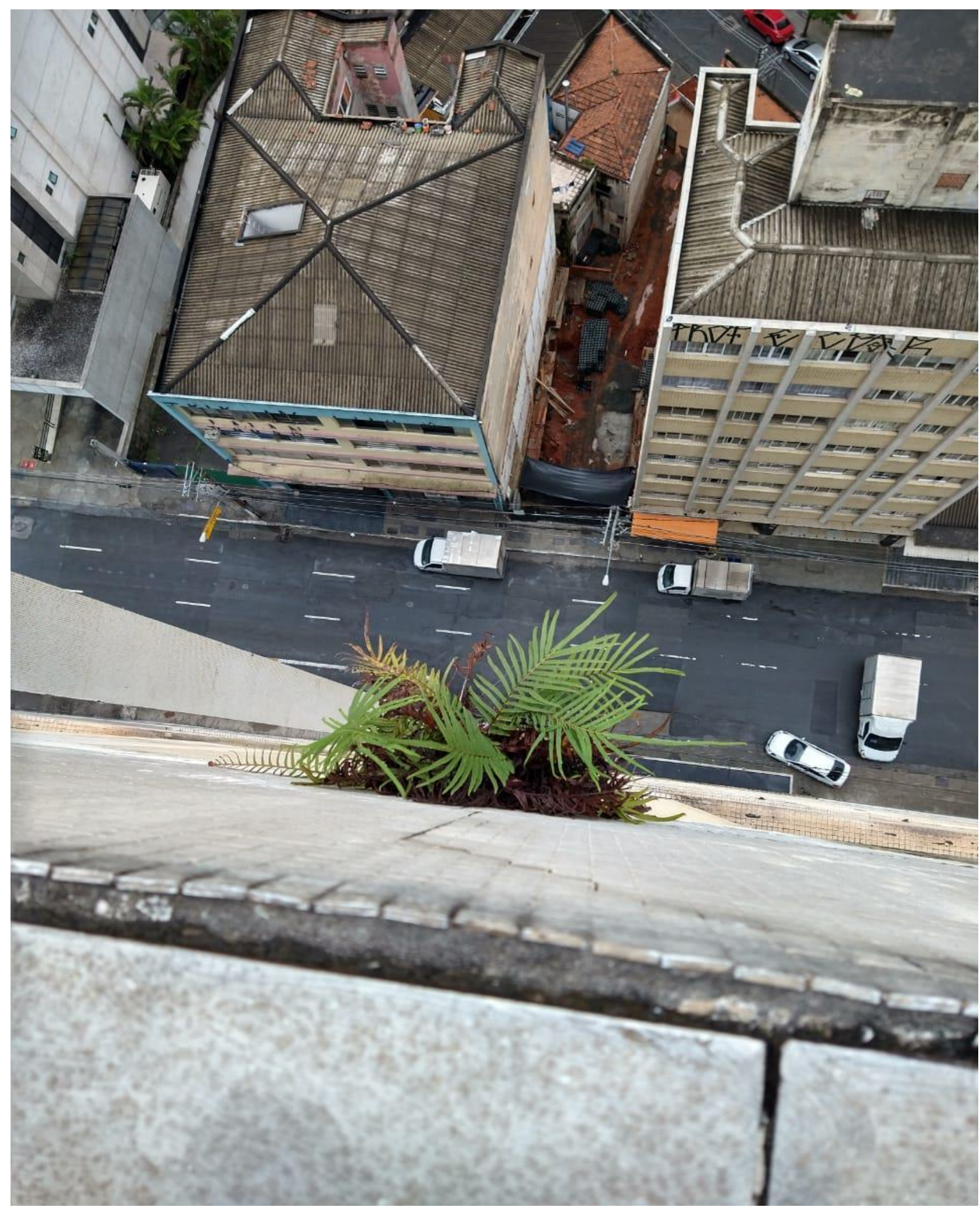

316 | Casas e descasos. Resistência e indiferenças 
RIF, Ponta Grossa/PR Volume 19, Número 42, p.312-320, Janeiro/Junho 2021

Foto 06: "Resistência na horizontal"

(Calçada da Alameda Santos, São Paulo - outubro/2020)

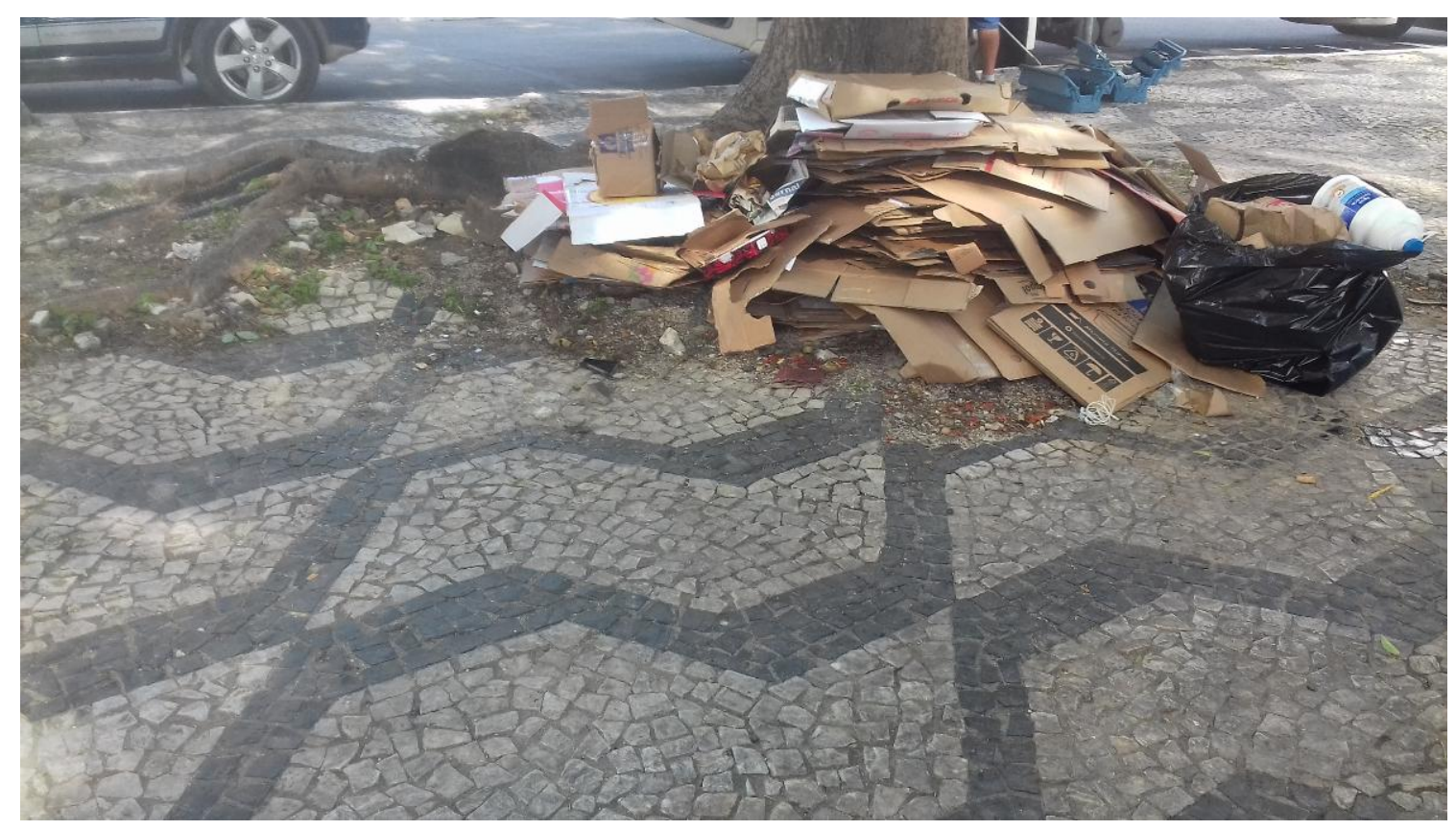

Foto 07: “Desrespeito despojado"

(Vagão de metrô, linha azul, São Paulo - setembro/2020)

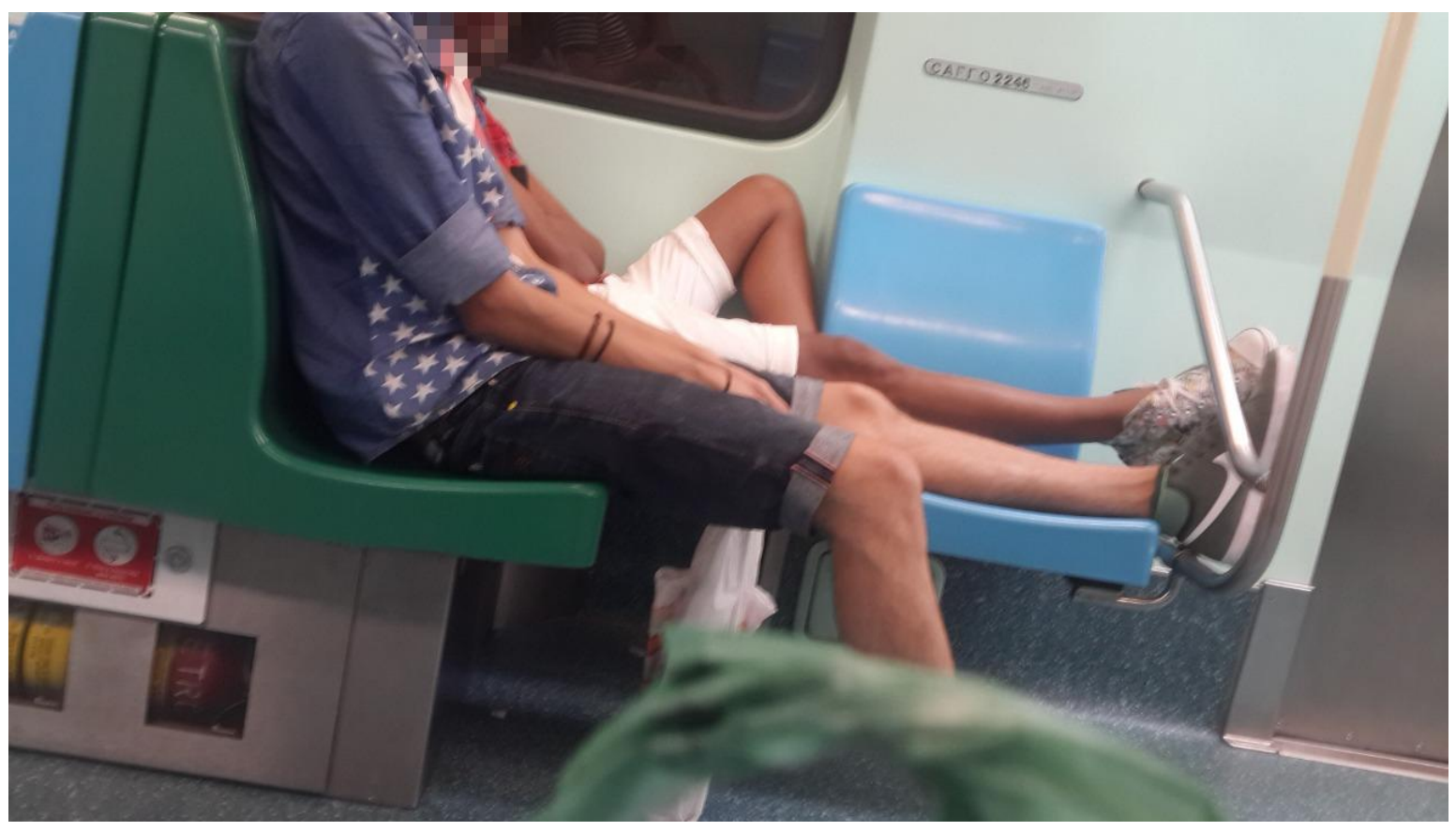


RIF, Ponta Grossa/PR Volume 19, Número 42, p.312-320, Janeiro/Junho 2021

Foto 08: "Desrespeito de salto alto".

(Vagão de metrô, linha azul, São Paulo - setembro/2020)

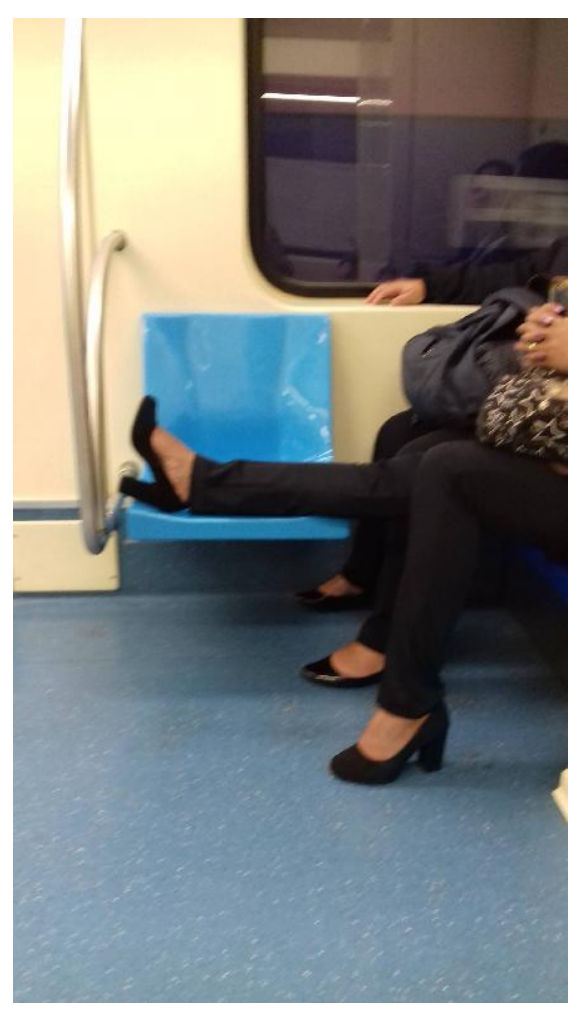

Foto 09: "Embasado: desrespeito solitário".

(Vagão de metrô, linha azul, São Paulo - setembro/2020)

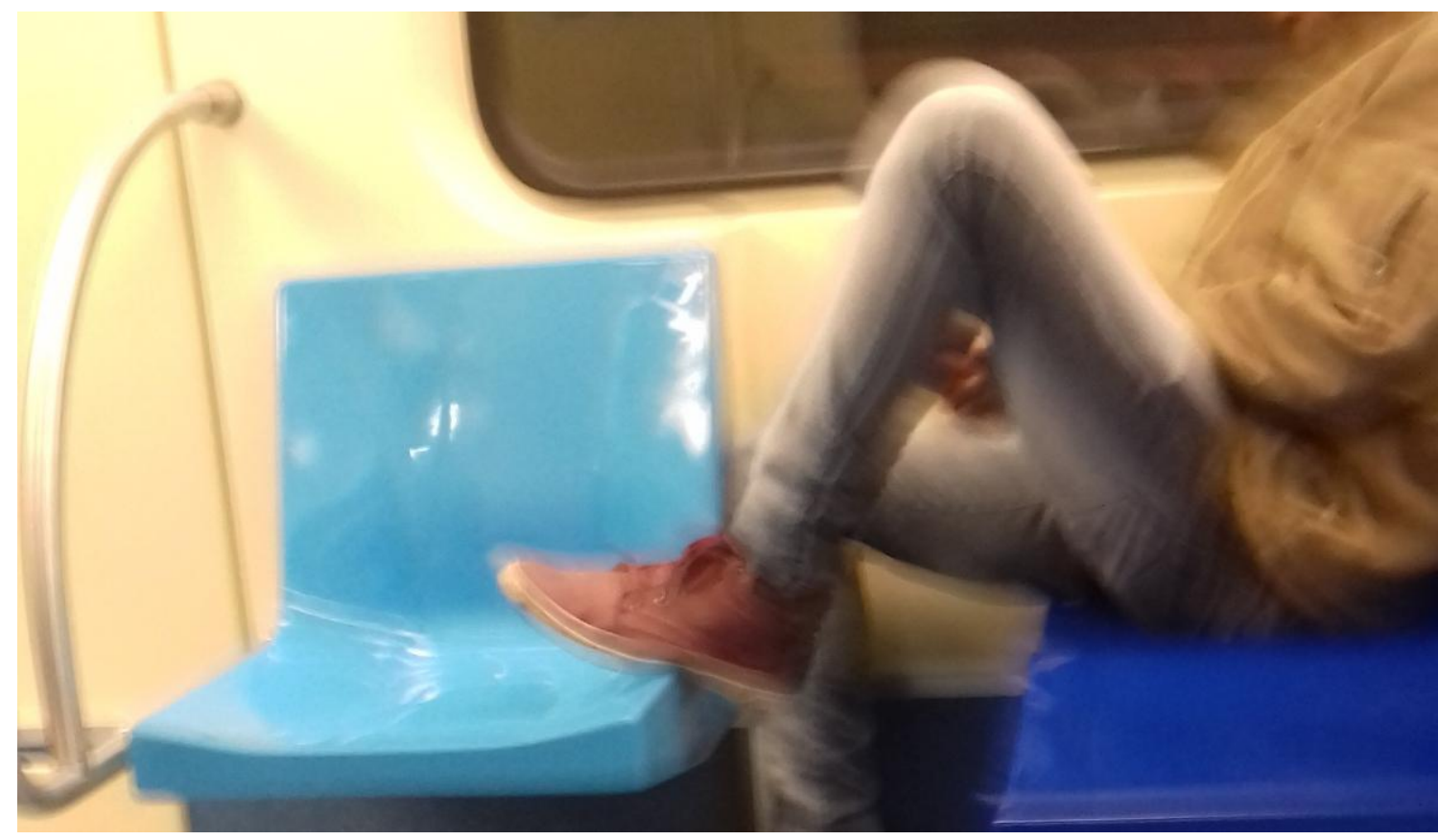

318 | Casas e descasos. Resistência e indiferenças 
RIF, Ponta Grossa/PR Volume 19, Número 42, p.312-320, Janeiro/Junho 2021

Foto 10: "Ignorando apelo de respeito".

(Vagão de metrô, linha azul, São Paulo - setembro/2020)

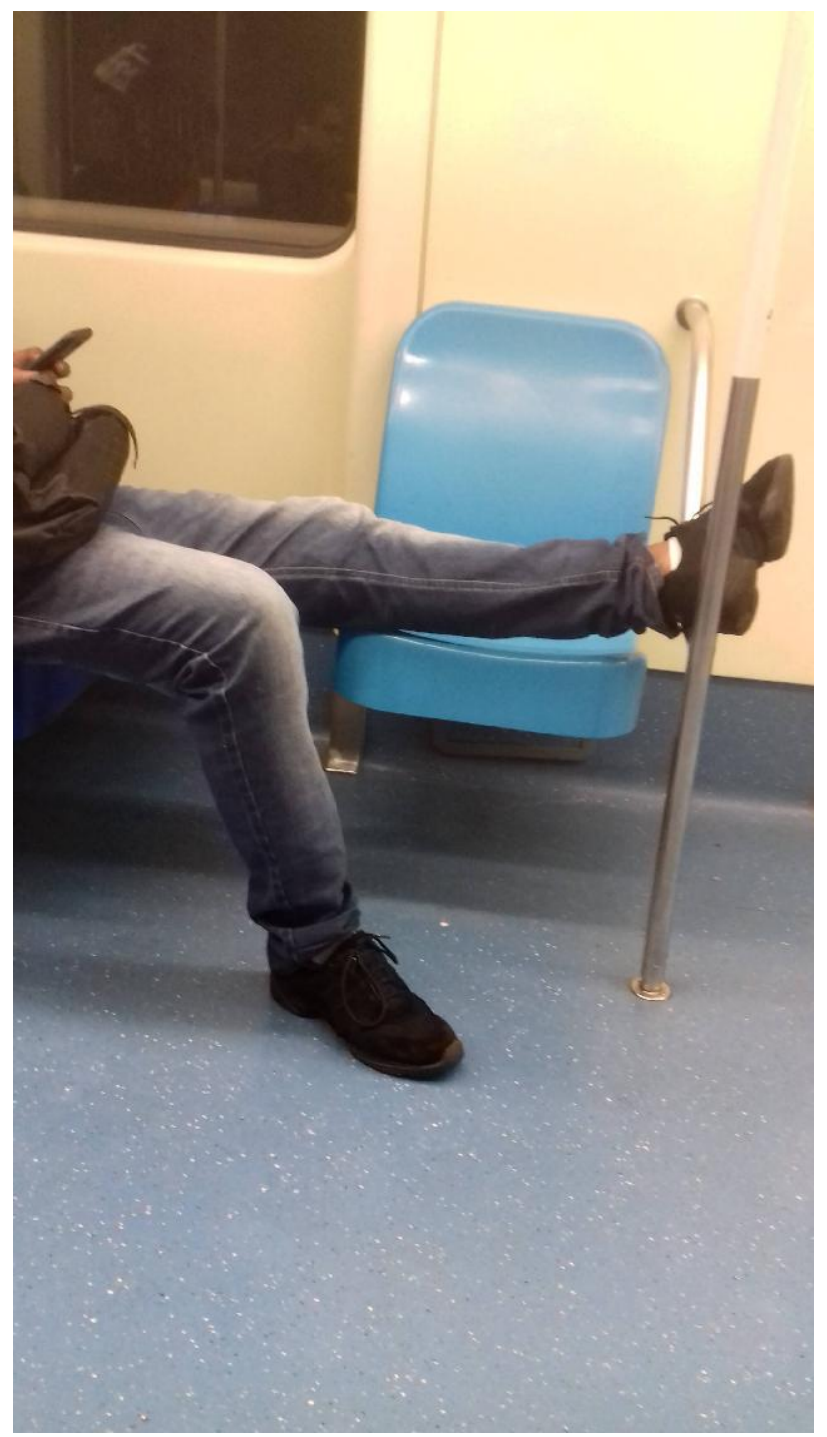




\section{RIF, Ponta Grossa/PR Volume 19, Número 42, p.312-320, Janeiro/Junho 2021}

\section{Referências}

BRIGGS, Asa; BURKE, Peter. Uma história social da mídia: de Gutenberg à Internet. 2. ed. Revista e ampliada. Rio de Janeiro: Zahar, 2006.

LIMA, Rafaela Pereira (org.). Mídias comunitárias, juventude e cidadania. 2. ed. Revista e atualizada. Belo Horizonte: Autêntica/Associação Imagem comunitária, 2006.

LIMA, Venício Artur de. Comunicação e cultura: as ideias de Paulo Freire. Rio de Janeiro: Paz e Terra, 1981.

SANTOS, Milton. Pobreza Urbana. São Paulo, Recife: Hucitec. 1978.

SOARES, Diniz Sousa Samara e CÂMARA, Vilela Clemente Gislene. Tecnologia e subjetividade: impactos do uso do celular no cotidiano de adolescentes. Belo Horizonte. Revista Pretextos, Revista da Graduação em Psicologia, PUC Minas, 2017. 